\title{
Study of Length of Umbilical Cord and Fetal Outcome: A Study of 1,000 Deliveries
}

\author{
Balkawade Nilesh Unmesh • Shinde Mangala Ashok
}

Received: 6 July 2011/Accepted: 23 April 2012/Published online: 3 October 2012

(C) Federation of Obstetric \& Gynecological Societies of India 2012

\begin{abstract}
Objective To study the correlation of umbilical cord length with fetal parameters like Apgar score, sex, weight, and length, and its effect on labor outcome.

Design Prospective study of 1,000 cases.

Setting Government Hospital

Material and Method Examination of umbilical cord was done for any loop around neck, trunk, etc; no. of loops of cord and positions; Knots of cord (True or false), any cord abnormalities. Fetal parameters recorded were sex, weight, and length of the newborn. Fetal outcome studied by Apgar score at 1 and $5 \mathrm{~min}$.

Results In our study, the cord length varied from 24 to $124 \mathrm{~cm}$. The mean cord length was $63.86 \mathrm{~cm}( \pm 15.69 \mathrm{~cm})$. Maximum cases seen were in the group of cord length between 51 and $60 \mathrm{~cm}$. Lower 5 th percentile was considered as short cord and upper 5th percentile was considered as long cord. Short-cord group was associated with significantly higher $(p<0.05)$ incidence of LSCS cases. Cord length did not vary according to the weight, length, and sex
\end{abstract}

Balkawade N. U., Ex-Senior Resident

Shinde M. A., Professor and Head

Dr. V. M. Govt. Medical College, Solapur, Maharashtra, India

Balkawade N. U. ( $\square)$, Ex-Senior Resident

502, Krishnashanti Residency, 139, Bhelkenagar, Kothrud,

Pune 411038, Maharashtra, India

e-mail: nileshbap@gmail.com of the baby. The incidence of all types of cord complications increases as the cord length increases $(p<0.001 *)$. Nuchal cords had higher mean cord length than in cases without nuchal cords $(\mathrm{p}<0.001)$. As the number of loops in a nuchal cord increases to more than two loops, the operative interference increases. The significance was tested by using a Chi-square test, and it was found to be statistically significant $(p<0.05)$. Nuchal cords were seen to be associated with more cases of fetal heart abnormalities $(p<0.001)$. There is higher incidence of variability in fetal heart rate with extremes of cord length $(p<0.001)$. The incidence of birth asphyxia was significantly more in long and short cords as compared to cords with normal cord length $(p<0.001)$.

Conclusion The present study showed that the length of umbilical cord is variable; however, maximum number of cases had normal cord length. Cases which had short and long cords constituted abnormal cord length. These cases had higher incidence of cord complications, increased incidence of operative interference, intrapartum complications, increased fetal heart rate abnormalities, and more chances of birth asphyxia. But cord length did not vary according to the weight, length, and sex of the baby.

\section{Introduction}

The umbilical cord is the lifeline of the fetus: "The baby's life hangs by a cord", as said by Ian Donald [1] aptly tells the importance of the umbilical cord. Viviparity means that 
the embryo develops inside the body of the mother. The best example is placental mammals. One of the most important parts of the fetoplacental unit is the umbilical cord. Complete cord occlusion often leads to fetal demise while intermittent obstruction has been associated with intrauterine brain damage. Compression and vasospasm in utero are important factors in fetal distress. Careful umbilical cord examination often reveals significant lesions which may be associated with these processes. As obstetricians, we realize this when a heavy toll of fetal life is due to cord complications.

Suspected fetal distress or a failure of the fetus to descend properly during labor is not uncommon. Often no explanation for such intrapartum complications is apparent. Complications associated with long or short umbilical cord may explain this enigma. Excessively short cords have been associated with a delay in second stage of labor, irregular fetal heart rate, placental abruption, rupture of umbilical cord, inversion of uterus, birth asphyxia, and cord herniation. Excessively long umbilical cords are associated with cord prolapse, torsion, true knot entanglement around the fetus, and delivery complications. There are more cases of fetal distress, fetal anomalies, and respiratory distress.

Cord length at term has appreciable variation, with extremes ranging from no cord (achordia) to lengths up to $300 \mathrm{~cm}$. At birth, the mature cord is about $50-60 \mathrm{~cm}$ in length and $12 \mathrm{~mm}$ in diameter. A long cord is defined as $>100 \mathrm{~cm}$ and a short cord as $<30 \mathrm{~cm}$. There may be as many as 40 spiral twists in the cord, as well as false knots and true knots. Short umbilical cords may be associated with adverse perinatal outcomes such as fetal growth restriction, congenital malformations, intrapartum distress, and a twofold risk of death (Krakowiak and associates, 2004) [2].

Though the pathogenesis of variability of umbilical cord length remains unclear, this study would provide information about the length of umbilical cord and its association with adverse fetal outcome.

\section{Methods}

This is a prospective study conducted in the Department of Obstetrics and Gynecology of Government Medical College set-up, from December 2007 to October 2009. The present study included 1,000 cases at random. The patients admitted to labor room with period of gestation $>37$ weeks were included in present study. Cases excluded from the study are

- preterm deliveries;

- multifetal gestation; and
- babies with major congential anomalies.

- Fetal heart rate was monitored clinically during labor. Mode of delivery, vaginal or cesarean, was noted.

- Examination of umbilical cord: it was being done at the time of delivery and after delivery for the following:

- the presence of any loop around neck, trunk, shoulder, etc.;

- cord loops tight or loose in LSCS cases;

- number of loops of cord and positions;

- knots of cord (true or false); and

- any cord abnormalities (cyst, hematoma, velamentous insertion, etc.).

- After the delivery of fetus, cord was clamped at two places and cut in between. From the cut end up to fetal umbilicus and placental attachment umbilical cord, length was measured and added. It was measured with flexible tape in $\mathrm{cm}$.

Number of umbilical arteries was not studied in present series. Type of insertion on the placenta was also noted. Adherent blood clots were removed from the maternal surface of the placenta. Placental weight was recorded in grams.

- Following parameters were recorded after the time of delivery.

1. Sex of the newborn.

2. Weight of the newborn: newborn was weighed after cutting the cord within half an hour of delivery.

3. Length of newborn - by keeping two hard plates, one at crown and one at the heel and distance between two plates measured and length of newborn measured (CHL).

4. Fetal outcome was studied by Apgar score at 1 and $5 \mathrm{~min}$. 
Fig. 1 Distribution of cases according to length of umbilical cord

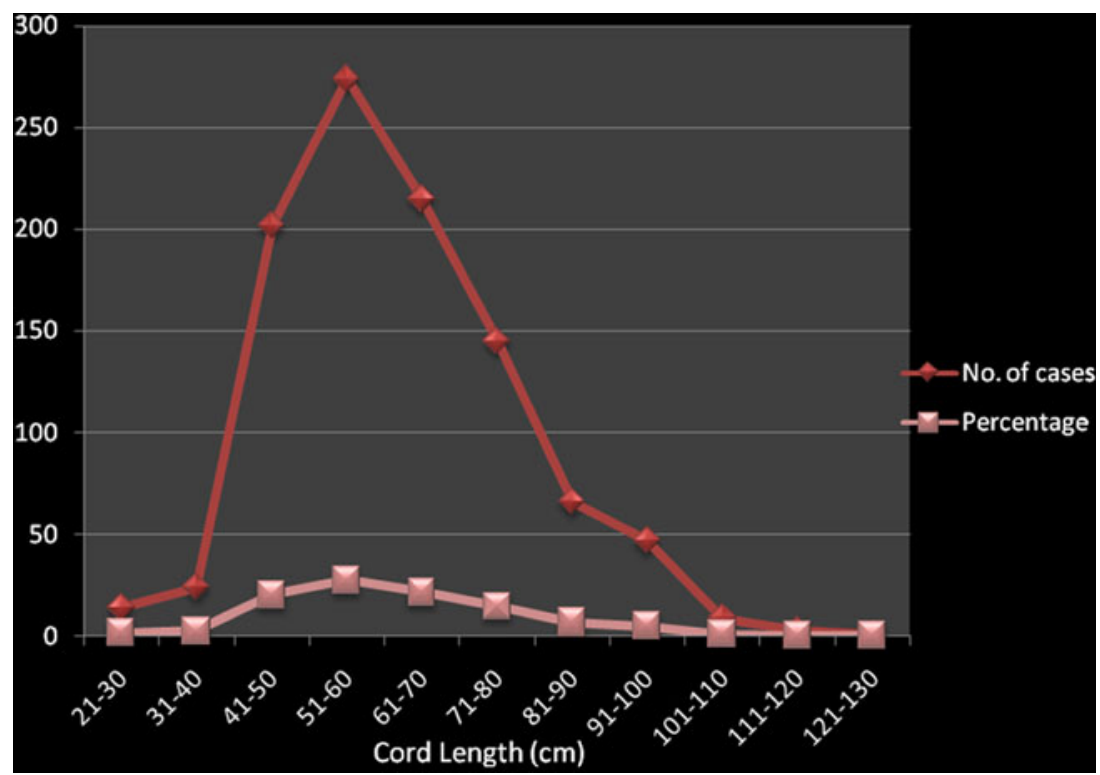

Table 1 Distribution of cases in groups according to length of umbilical cord

\begin{tabular}{lrlc}
\hline $\begin{array}{l}\text { Length of } \\
\text { cord }\end{array}$ & $\begin{array}{l}\text { No. of } \\
\text { cases }\end{array}$ & $\begin{array}{l}\text { Percentage } \\
(\%)\end{array}$ & $\begin{array}{l}\text { Mean umbilical } \\
\text { cord length in cm }\end{array}$ \\
\hline Short & 59 & 5.9 & $37.06 \pm 6.34$ \\
Normal & 888 & 88.8 & $63.44 \pm 11.93$ \\
Long & 53 & 5.3 & $100.86 \pm 6.51$ \\
Total & 1000 & 100 & \\
\hline
\end{tabular}

type $(32.4 \%)$ both of which are normal cord attachments. There were very few cases of abnormal cord attachment including marginal and velamentous insertion, 0.3 and $0.1 \%$, respectively.

Cases of short-cord group had maximum cases of LSCS $(40.7 \%)$, than cases with long $(24.5 \%)$ or normal $(23.6 \%)$ cord length. Normal-cord group cases had maximum no. of vaginal delivery cases $(76.4 \%)$ more than $75.5 \%$ for long-cord group and $59.3 \%$ for short-cord group. Short-cord group was associated with significantly higher $(p<0.05)$ incidence of LSCS cases.

Of the total, nuchal coiling was seen in $20.7 \%$ (207 cases). In cases with a long cord the incidence of nuchal coiling is $67.9 \%$ (36 cases), while in cases with a short cord it was 1.7 and $19.1 \%$ in cases with a normal cord length. One case had five tight loops of cord around neck. The cord length was $110 \mathrm{~cm}$ in this case with central cord insertion, the duration of second stage of labor was increased, and LSCS had to be done for fetal distress. After delivery, Apgar score of the baby was low $[$ Apgar $=4$ (1 $\mathrm{min})$ and $6(5 \mathrm{~min})]$. NICU admission of the baby had to be done. In long-cord group, $7.5 \%$ cases had true knots, whereas in normal-cord group $1.3 \%$ cases were having true knots. There were eight cases of cord prolapse of which two cases had a long cord, and six cases had a normal cord length (Table 2).

The incidence of operative interference increases in cases with cord complications. For all the cases of cord prolapse, LSCS was done. The percentage of total LSCS cases in the present study was $24.7 \%$ (247 per 1,000 cases). Thus, cord complications were associated with more incidences of LSCS [nuchal cord $35.7 \%$, true knot $25 \%$, and $100 \%$ for cord prolapse and cord hematoma].

As the number of loops in a nuchal cord increases to more than two loops, the operative interference increases. The significance was tested by using a Chi-square test, and it was found to be statistically significant $(p<0.05)$ (Table 3) .

Mean cord length in cases with nuchal cords was $77.24 \pm 15.71$ and that in cases without nuchal cords was $60.37 \pm 15.69$. Umbilical cords with nuchal cords had higher mean cord length than in cases without nuchal cords. Significance was tested by using $Z$ test and was found to be highly significant $(p<0.001)$.

True knots were associated with a higher mean cord length of $77.56 \mathrm{~cm}$ for cases with true knots than those cords without this abnormality. The difference is statistically significant $(p<0.001)$.

There is no significant difference $(p>0.05)$ in the mean cord length with respect to the sex and length of the baby.

Fetal heart rate was monitored by intermittent auscultation as continuous fetal monitoring was not possible. Bradycardia was seen in $32.7 \%$ of short-cord group and $41.5 \%$ in long-cord group. There is higher incidence of variability in fetal heart rate with extremes of cord length: bradycardia and tachycardia are seen more with short and long cords than with normal cords. It was highly significant $(p<0.001)$ statistically using the Chi-square test. 
Table 2 Umbilical cord length and incidence of cord complications

\begin{tabular}{|c|c|c|c|c|c|c|}
\hline \multirow[t]{2}{*}{ Umbilical cord length } & \multicolumn{6}{|c|}{ Cord complication } \\
\hline & No. of cases & $\begin{array}{l}\text { Nuchal cords } \\
(n=207)(\%)\end{array}$ & $\begin{array}{l}\text { True knot } \\
(n=16)(\%)\end{array}$ & $\begin{array}{l}\text { Cord prolapse } \\
(n=8)(\%)\end{array}$ & $\begin{array}{l}\text { Cord hematoma } \\
(n=1)\end{array}$ & Total $(n=232)$ \\
\hline Short cord & 59 & $1(1.7)$ & 0 & 0 & 0 & 1 \\
\hline Normal & 888 & $170(19.1)$ & $12(1.3)$ & $6(0.67)$ & 1 & 189 \\
\hline Long* cord & 53 & $36(67.9)$ & $4(7.5)$ & $2(3.8)$ & 0 & 42 \\
\hline
\end{tabular}

The incidence of all types of cord complications increases as the cord length increases

$* p<0.001$

Table 3 No. of nuchal cords and mode of delivery

\begin{tabular}{|c|c|c|c|c|}
\hline \multirow{2}{*}{$\begin{array}{l}\text { No. of } \\
\text { coils }\end{array}$} & \multirow{2}{*}{$\begin{array}{l}\text { No. of } \\
\text { cases }(\%)\end{array}$} & \multirow{2}{*}{$\begin{array}{l}\text { Mean cord } \\
\text { length } \\
\text { (in } \mathrm{cm} \pm \mathrm{SD} \text { ) }\end{array}$} & \multicolumn{2}{|c|}{ Mode of delivery } \\
\hline & & & $\begin{array}{l}\text { Vaginal } \\
(\%)\end{array}$ & $\begin{array}{l}\text { LSCS } \\
(\%)\end{array}$ \\
\hline One loop & $124(12.4)$ & $68.55 \pm 15.69$ & $88(71)$ & $36(29)$ \\
\hline Two loops & $67(6.7)$ & $88.47 \pm 15.78$ & $31(46.3)$ & $36(53.7)$ \\
\hline $\begin{array}{l}\text { Three } \\
\text { loops }\end{array}$ & $13(1.3)$ & $96.15 \pm 15.87$ & $13(100)$ & 0 \\
\hline Four loops & $02(0.2)$ & $100 \pm 16.05$ & $01(50)$ & $01(50)$ \\
\hline Five loops & $01(0.1)$ & 110 & 0 & $01(100)$ \\
\hline
\end{tabular}

The incidence of birth asphyxia was significantly more in long and short cords as compared to cords with normal cord length. When studied in comparison to cords with normal length, short cords and long cords were associated more commonly with birth asphyxia: Apgar score of $\leq 6$. Birth asphyxia was seen maximum $(56.6 \%)$ in cases with long cord length. The difference was measured by using Chi-square test. It was statistically highly significant $(\mathrm{p}<0.001)$.

Maximum still births (13.2\%) in long-cord group and maximum early neonatal deaths $(11.86 \%)$ in short-cord group. Still births and early neonatal deaths are more with short- and long-cord groups than those in normal cord groups. It was found that perinatal mortality was more with short and long cords than that in normal ones, and the difference was highly significant $(p<0.001)$.

\section{Discussion}

\section{Umbilical Cord Length}

Mean umbilical cord length in the present series is comparable to mean umbilical cord length of other authors. The length of the umbilical cord varies widely. Cord length varies between 0 [3] to $300 \mathrm{~cm}$ [4]. The average length of the umbilical cord is usually between 50 and $60 \mathrm{~cm}$ [5]. This study is comparable with the findings of Mishra et al.
Table 4 Distribution of cases according to changes in fetal heart rate (FHR)

\begin{tabular}{lccl}
\hline Length of cord & \multicolumn{1}{l}{ Normal } & Bradycardia & Tachycardia \\
\hline Short & $33(56.8 \%)$ & $19(32.7 \%)$ & $06(10.3 \%)$ \\
Normal & $731(82.9 \%)$ & $135(15.3 \%)$ & $15(1.7 \%)$ \\
Long & $27(50.9 \%)$ & $22(41.5 \%)$ & $04(7.5 \%)$ \\
Total & 791 & 175 & 25 \\
\hline
\end{tabular}

[6], where the average cord length was $50-60 \mathrm{~cm}$ and Malpas [4] where the maximum cord length was between 46 and $79 \mathrm{~cm}$.

Eccentric insertion of the cord is the commonest finding. In Fox's [7] series of 1,000 cases, it was seen in $62 \%$ cases, and in our study it was found in $67.2 \%$ cases.

In the study of Mishra et al. [6] criteria for short cord was $<20 \mathrm{~cm}$, long cord $>100 \mathrm{~cm}$, and control group between 50 and $60 \mathrm{~cm}$. They also included the same set of patients, i.e., full term from 38 to 40 weeks of gestation, and cases with maternal and fetal complications were excluded from the study. In present study, normal-cord group includes $36-84 \mathrm{~cm}$, and so percentage of LSCS in both studies are comparable, and there are increased incidence of LSCS in short- $(45.45 \%)$ and long-cord $(56.66 \%)$ groups.

There was no difference in the overall mode of delivery for the cord, entangled, or non-entangled and all twins, although cord entanglement was more prevalent in spontaneous vertex vaginal deliveries [8].

This increased incidence of operative interference may be due to cord abnormalities (coiling around neck, body cord abnormalities, and true knot) in long-cord group (Table 4). The percentage of total LSCS cases in the present study was $24.7 \%$ ( 247 per 1,000 cases). The cord complications were associated with more incidences of LSCS [nuchal cord $35.7 \%$, true knot $25 \%$, and $100 \%$ for cord prolapse and cord hematoma].

Lamonica et al. [9] in their study of "minimum cord length to allow spontaneous vaginal delivery" stated that the uterine axis and birth canal are not so long as to impede 
spontaneous vaginal delivery in the presence of a short umbilical cord. They also reported that placental location makes no difference except perhaps when the cord is excessively short.

In the present series, there is significant increased incidence of LSCS in short-cord group. There is an increased incidence of normal delivery $(74.82 \%)$ in normal-cord group compared with short- and long-cord group.

The incidences of all types of cord complications increase as the cord length increases. The present study is comparable with the study by Rayburn et al. [10] and Greenhill [11]. Both the studies have shown statistically significant $(p<0.001)$ association of cord complications with increase in the cord length (i.e., long cords).

In the present study, long cords were associated more with loops around neck and also with increased fetal heart rate changes. The exact cause of a slow neonatal heart is not known: it is probably due to vagotonia rather than true hypoxia [12].

In the present study, out of the 1,000 cases studied, 207 had nuchal cords (i.e., $20.7 \%$ ). The incidence of multiple nuchal cords was slightly more than those given in other study groups. In our study, as the number of loops of cord around neck increased, the mean cord length was found to be more: $68.55 \mathrm{~cm}$ for one loop, $88.47 \mathrm{~cm}$ for two loops, and $96.15 \mathrm{~cm}$ for three loops. Longer cords tend to become looped around neck. Nuchal coiling can occur in shorter cords, in which the cord tends to be more tightly wrapped around the infant's neck. This was also shown by Rogers et al. [13].

In our study, the mean cord length in cases with a true knot was $56.25 \mathrm{~cm}( \pm 4.23)$ which was longer than the mean cord length $(p<0.05)$.

In our study, there were eight cases of cord prolapse $(0.8 \%)$. The mean cord length in cases with cord prolapse was $71.87 \mathrm{~cm}( \pm 15.8)$ which was more than cases without cord prolapse. However, it was statistically insignificant $(p>0.05)$ as the number of cases was less. Thus, we confirm the findings of Sarwano et al. [14] who showed that the risk of complications increased lineraly with the cord length. The reported incidence of prolapse of the umbilical cord varies between 0.2 and $0.6 \%$ of births.

In the present series, out of the 1,000 cases, babies having birth asphyxia (Apgar $\leq 6)$ were 234 (i.e., $23.4 \%$ ). Out of these incidences of severe birth, asphyxia was maximum in long-cord groups $(56.6 \%)$. In short-cord group, it was $37.3 \%$ compared to normal-cord group $(20.5 \%)$. Higher percentage of birth asphyxia in long-cord group may be additionally due to more incidences of cord abnormalities (nuchal cord, true knot, and cord prolapse). In case of short cord, excessive traction will cause spasm of umbilical vessels; premature separation of placenta will lead to increase in birth asphyxia.
The incidence of fetal heart rate abnormalities was more in cases with short and long cords in our study. The study is comparable in its percentage of fetal heart abnormality in relation to variable cord length with the study by Rayburn [10].

There were more cases of birth asphyxia in short- and long-cord groups as compared to cords with normal length.

On the other hand, Atalla et al. [15] found no relation between umbilical cord indices and intrapartum FHR decelerations, meconium staining of the amniotic fluid, or mode of delivery. Spellacy et al. [12] showed that all cord complications showed significantly low Apgar scores at 1 min.

Shrestha [16] studied Nuchal cord and perinatal outcome. Neonatal outcome was analyzed by Apgar score at 1 and $5 \mathrm{~min}$ and the need for neonatal unit admission. Apgar score $<7$ at $1 \mathrm{~min}$ was present in $24.78 \%(n=29)$ of newborns in study group and $14.68 \%(n=58)$ of newborns in control group, which was statistically significant $(p=0.01)$.

\section{Conclusion}

The present study showed that the length of umbilical cord is variable; however, maximum number of cases had normal cord length. Cases which had short and long cords constituted abnormal cord length. These cases had higher incidence of cord complications, increased incidence of operative interference, intrapartum complications, increased fetal heart rate abnormalities and more chances of birth asphyxia.

Thus, this study shows the importance of the knowledge of cord length.

The findings of a worrisome fetal heart rate tracing, or failure of fetal descent during labor is not uncommon. A keen obstetrician would not only be interested in proper management of such complications, but also in documenting these important findings for further research.

There is a huge arena for research in this field as what we are seeing is just the tip of an iceberg. The challenge should be taken up, and newer equipment and strategies should be developed to analyze and avoid cord complications. This would decrease the incidences of the perinatal morbidity and mortality due to cord complications in the future and help in realizing the expections for the delivery of a healthy baby.

Acknowledgments Our sincere thanks go to Dr Vasanti Munot, Ex-Hon. Ass.Prof.; my Ex-PG Guide, Dr Kurdukar, Asso. Prof.; Dr Vidya Tirankar, Asso. Prof., Department of Obstetrics and Gynecology, Dr V. M. Govt. Medical College, Solapur for guiding us through the study. 


\section{References}

1. Ian Donald. Practical Obstetric Problems. 1994; 417.

2. Krakowiak P, Smith EN, de Bruyn G, et al. Risk factors and outcomes associated with a short umbilical cord. Obstet Gynecol. 2004;103:119-27.

3. Browne FJ. Abnormalities of the Umbilical Cord which may cause Antenatal Death. J Obstet Gynaecol Br Emp. 1925;32:17-48.

4. Malpas P. Length of the human umbilical cord at term. Br Med J. 1964;14(1):673-4.

5. Blanc WA. Pathology of the placenta and of perinatal deaths. In: Niswander KR, Gordon M, editors. The women and their pregnancies. Philadelphia-London-Toronto: Saunders; 1972.

6. Mishra R, Vijayalaxmi P, Nirmala Kumari J. Correlation of the length of umbilical cord of the fetus with outcome of labor. J Obstet Gynaecol India. 1987;37:781.

7. Harld F, Elston Cw. Pathology of the umbilical cord. pathology of the placenta. Major problems in pathology. London: Saunders; 1978.

8. Yampolsky M, Salafia CM, Shlakhter O, et al. Centrality of the umbilical cord insertion in a human placenta influences the placental efficiency. Placenta. 2009;30(12):1058-64.
9. LaMonica GE, Wilson ML, Fullilove AM, et al. Minimum cord length that allows spontaneous vaginal delivery. J Reprod Med. 2008;53(3):217-9.

10. Rayburn WF, Beynen A, Brinkman DL. Umbilical cord length and intraparturn complications. Obstet Gynaecol. 1981;57:450.

11. Greenhill JP. Anatomy, anomalies, and prolapse of the umbilical cord. Clin Obstet Gynecol. 1962;5:982.

12. Spellacy WN, Gravem H, Fisch RO. The umbilical cord complications of true knots, nuchal coils and cords around the body. Am J Obstet Gynaecol. 1966;94(8):1136-42.

13. Rogers MS, Ip YW, Qin Y, et al. Relationship between umbilical cord morphology and nuchal cord entanglement. Acta Obstet Gynecol Scand. 2002;82:32-7.

14. Sarwano E, Disse WS, Oudesluys Murphy HM, et al. Umbilical cord length and intrauterine well being. Paediatr Indones. 1991;31:136-40.

15. Atalla RK, Abrams K, Bell SC, et al. Newborn acid-base status and umbilical cord morphology. Obstet Gynecol. 1953;92(55): $865-86$.

16. Shrestha NS, Singh N. Nuchal cord and perinatal outcome. Kathmandu Univ Med J. 2007;19:360-3. 